\title{
"Novel" Triggers of Herpesvirus Reactivation and Their Potential Health Relevance
}

\author{
Tobias Stoeger ${ }^{1 *}$ and Heiko Adler ${ }^{2,3 *}$ \\ ${ }^{1}$ Institute of Lung Biology and Disease, Comprehensive Pneumology Center, Helmholtz Zentrum München - German \\ Research Center for Environmental Health $(\mathrm{GmbH})$, Neuherberg, Germany, ${ }^{2}$ Research Unit Lung Repair and Regeneration, \\ Comprehensive Pneumology Center, Helmholtz Zentrum München - German Research Center for Environmental Health \\ $(\mathrm{GmbH})$, and University Hospital Grosshadern, Ludwig-Maximilians-University, Munich, Germany, ${ }^{3}$ German Center for Lung \\ Research (DZL), Giessen, Germany
}

Keywords: herpesvirus, reactivation, nanoparticle, non-canonical triggers, health relevance

OPEN ACCESS

Edited by:

Benjamin G. Dewals,

University of Liege, Belgium

Reviewed by

Bénédicte Machiels,

University of Liege, Belgium

Xiaozhen Liang,

Institut Pasteur of Shanghai (CAS),

China

Tiffany Reese,

University of Texas Southwestern

Medical Center, United States

*Correspondence:

Tobias Stoeger

tobias.stoeger@

helmholtz-muenchen.de

Heiko Adler

h.adler@helmholtz-muenchen.de

Specialty section:

This article was submitted to

Virology,

a section of the journal

Frontiers in Microbiology

Received: 09 October 2018

Accepted: 11 December 2018

Published: 07 January 2019

Citation:

Stoeger T and Adler H (2019) "Novel"

Triggers of Herpesvirus Reactivation

and Their Potential Health Relevance.

Front. Microbiol. 9:3207.

doi: 10.3389/fmicb.2018.03207
After primary infection, herpesviruses persist for life in their hosts in a latent stage (Adler et al., 2017). Different subfamilies of herpesviruses establish latency in specific and different sets of cells (Pellett and Roizman, 2013; Lieberman, 2016). The latent stage can be interrupted by periods of lytic replication, termed reactivation. Reactivation is important for viral spread to new hosts or for the maintenance of the viral reservoir in the host. Usually, reactivation is not associated with disease but under certain circumstances, it may be accompanied by clinical symptoms. The stimuli and the precise molecular mechanisms that lead to reactivation from the latent state are not fully understood and can differ from one herpesvirus to another.

\section{HERPESVIRUS REACTIVATION IN THE HUMAN HOST BY "CLASSICAL" TRIGGERS}

A number of stimuli that trigger reactivation in humans are known for a long time - we term them as "classical" triggers of herpesvirus reactivation (Figure 1): (i) Alphaherpesviruses, e.g., latent HSV-1 in neurons of various ganglia, are for example reactivated by local injury to tissues innervated by latently infected neurons or by systemic physical or emotional stress, fever and microbial co-infection as well as UV-exposure or hormonal imbalance (Roizman and Whitley, 2013; Roizman et al., 2013). (ii) Reactivation of betaherpesviruses, for example $\mathrm{CMV}$, is observed commonly in the setting of immunosuppression, particularly where allogeneic stimulation and pro-inflammatory cytokines are present and stimulate cellular differentiation to macrophages or dendritic cells (Stinski and Meier, 2007; Liu et al., 2013; Dupont and Reeves, 2016; Lieberman, 2016). (iii) Stimuli that induce reactivation of gammaherpesviruses, for example EBV, are differentiation of B cells into plasma cells through antigen stimulation of the B-cell receptor. In vitro, and potentially likewise in vivo, also cytokines including TGF-beta can induce B-cell activation and thus result in lytic EBV infection. Additionally, host cell stress, induced for example by chemotherapy or body irradiation, can reactivate latent EBV. In cell culture, EBV reactivation can also be triggered by phorbol ester 12-0-tetradecanoyl phorbol-13-acetate (TPA), sodium butyrate or calcium ionophores (Kenney, 2007; Murata, 2014). Many of these reactivation triggers activate classical signal transduction pathways, including protein kinase $\mathrm{C}, \mathrm{p} 38$ kinase, cJun N-terminal kinase (JNK), ERK kinase and PI3 kinase. In conclusion, there are many settings of a specific herpesvirus, a specific host cell and a specific stimulus, determining the transition from latency to lytic cycle (Kenney, 2007; Murata, 2014; Dupont and Reeves, 2016; Cliffe and Wilson, 2017). 


"Classical" triggers of
reactivation:
Fever
Microbial co-infection
UV-light
Stress
Tissue injury
Hyperthermia
Hormonal imbalance
Allogeneic stimulation
Cytokines
Cell differentiation
Toxic stimuli
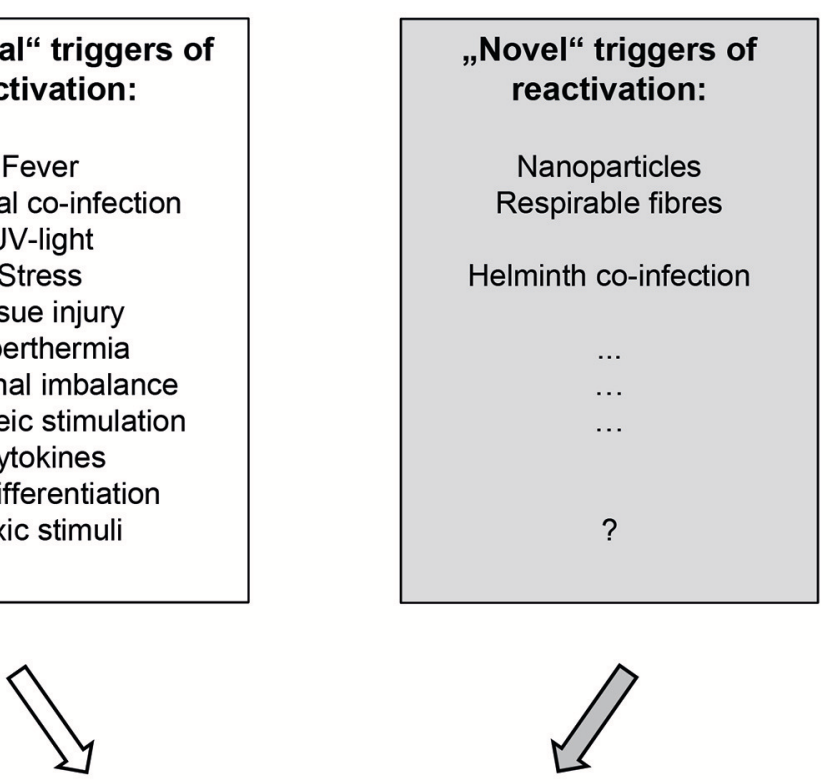

Common or different pathways?

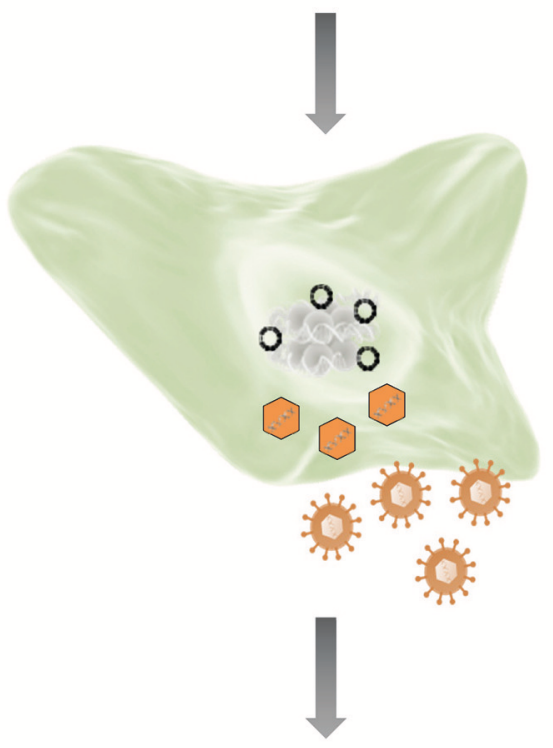

Disease associated with reactivation

\section{Key: Nucleosome O Virus episome@ Virus capsid Virus particle}

FIGURE 1 | "Classical" and "novel" triggers of herpesvirus reactivation. Both types of triggers are able to induce reactivation of latent herpesviruses. The respective signal transduction pathways that are activated may be shared, or may vary depending on the stimulus, the cell type and the virus. Although reactivation is usually not associated with disease, it may be accompanied by clinical symptoms under certain circumstances. 


\section{"NOVEL" TRIGGERS OF HERPESVIRUS REACTIVATION}

Beside the above described "classical" triggers of herpesvirus reactivation, we propose the existence of additional, so far unappreciated "novel" triggers of herpesvirus reactivation (Figure 1). This proposal is based on recent findings by us and by others. Reese et al. found that helminth coinfection reactivated murine gammaherpesvirus 68 (MHV-68) in vivo in an IL-4/Stat6-dependent manner (Reese et al., 2014; Reese, 2016). We demonstrated that cells persistently infected with murine or human gammaherpesviruses responded to nanoparticle (NP) exposure by reactivation of latent virus and by restoring a molecular signature found during productive infection (Sattler et al., 2017). In our study, we exposed cells or mice latently infected with MHV-68 to different NP. In vitro, NP-exposure resulted in expression of lytic viral genes and virus production. In vivo, an increase in lytic viral proteins and gene expression was observed in lungs and cells from bronchoalveolar lavage. The patterns of gene and metabolite expression in whole lung tissue were strikingly similar to acute virus infection. In human cells latently infected with EBV, NP-exposure also induced virus production. The carbonaceous NPs used in our study were (i) carbon black like surrogates of environmental NPs, derived for example from combustion or mass production, as well as (ii) carbon nanotubes (CNTs) as examples for promising new materials in technology and biomedicine. Thus, it is well-conceivable that other types of NPs, derived from different materials, might also be able to induce herpesvirus reactivation. Furthermore, a variety of additional factors, present in the environment but so far not considered to be triggers of herpesvirus reactivation, might be relevant too.

\section{POTENTIAL HEALTH RELEVANCE OF "NOVEL" INDUCERS OF HERPESVIRUS REACTIVATION}

The finding, that helminth co-infection wakes up dormant gammaherpesviruses might have major implications for human health. This has already been discussed by Maizels and Gause (Maizels and Gause, 2014). Equally, our discovery that exposure to NP is able to activate gammaherpesviruses that are dormant in the lung may have consequences for human health in an environment with an increasing exposure to NP. Both innate and adaptive immune responses are modulated by NP, leading for example to immunosuppression or hypersensitivity (Pallardy et al., 2017). Exposure to ambient respirable particles such as man-made mineral fibers or vehicle exhaust emissions have been associated with various adverse health effects (Seaton et al., 2010). When inhaled, NP deposit efficiently and persistently in the alveolar region of the respiratory tract. Their proinflammatory properties shape chronic lung diseases like asthma, chronic obstructive pulmonary disease (COPD), pulmonary fibrosis or cancer (Byrne and Baugh, 2008; Morgenstern et al., 2008; Bonner, 2010; Sese et al., 2018; Siroux and Crestani, 2018). The rapid expansion of nanotechnology bears the risk of increasing the incidences of these diseases. Herpesvirus infections may also contribute to the development of chronic pulmonary diseases (Meneghin and Hogaboam, 2007; Vannella and Moore, 2008; Naik and Moore, 2010; Kropski et al., 2012). However, potentiation by a combined exposure to both triggers has not been investigated. We propose that repeated NP exposure and concomitant herpesvirus reactivation result in chronic inflammatory and remodeling processes in the lung, for example by permanently stimulating an aberrant immune response, finally leading to immunopathology and disease development. It is tempting to speculate that inhaled NP might also be among the unknown triggers suspected to enable propagation of additional resident viruses of the airway virome, thereby causing exacerbations of various lung diseases (Marsland and Gollwitzer, 2014).

Following exposure via various routes including inhalation, $\mathrm{NP}$ are not only found in the lung but also deposited in numerous organs including the central nervous system (Hong et al., 2017; You et al., 2018). Inhaled nanoparticles can translocate into the systemic circulation and have been shown to accumulate at sites of vascular inflammation and disease (Miller et al., 2017). There is a long term controversy with regard to the contribution of herpesviruses to other chronic diseases beyond the lung: For example, CMV has been associated with coronary heart disease (atherosclerosis) (Du et al., 2018), and EBV, HHV-6 and VZV with multiple sclerosis (Geginat et al., 2017). We propose that also in these disease entities, an interaction of NP with latent herpesviruses may result in reactivation with subsequent chronic inflammation and disease development.

Taken together, future studies on effects of NPinduced herpesvirus reactivation on human health, possible treatments and potential regulatory measures are warranted.

\section{AUTHOR CONTRIBUTIONS}

All authors listed have made a substantial, direct and intellectual contribution to the work, and approved it for publication.

\section{FUNDING}

The work in the laboratories of TS and HA was funded by intramural funding for Environmental Health Projects of the Helmholtz Zentrum München - German Research Center for Environmental Health $(\mathrm{GmbH})$.

\section{ACKNOWLEDGMENTS}

We are grateful to Barbara Adler (Gene Center, Munich, Germany) and the members of our institutes for helpful discussions. 


\section{REFERENCES}

Adler, B., Sattler, C., and Adler, H. (2017). Herpesviruses and their host cells: a successful liaison. Trends Microbiol. 25, 229-241. doi: 10.1016/j.tim.2016.11.009

Bonner, J. C. (2010). Nanoparticles as a potential cause of pleural and interstitial lung disease. Proc. Am. Thorac. Soc. 7, 138-141. doi: 10.1513/pats.200907-061RM

Byrne, J. D., and Baugh, J. A. (2008). The significance of nanoparticles in particleinduced pulmonary fibrosis. Mcgill J. Med. 11, 43-50.

Cliffe, A. R., and Wilson, A. C. (2017). Restarting lytic gene transcription at the onset of herpes simplex virus reactivation. J. Virol. 91, JVI-16. doi: 10.1128/JVI.01419-16

Du, Y., Zhang, G., and Liu, Z. (2018). Human cytomegalovirus infection and coronary heart disease: a systematic review. Virol. J. 15, 31-0937. doi: 10.1186/s12985-018-0937-3

Dupont, L., and Reeves, M. B. (2016). Cytomegalovirus latency and reactivation: recent insights into an age old problem. Rev. Med. Virol. 26, 75-89. doi: $10.1002 /$ rmv.1862

Geginat, J., Paroni, M., Pagani, M., Galimberti, D., De, F. R., Scarpini, E., et al. (2017). The enigmatic role of viruses in multiple sclerosis: molecular mimicry or disturbed immune surveillance? Trends Immunol. 38, 498-512. doi: 10.1016/j.it.2017.04.006

Hong, F., Yu, X., Wu, N., and Zhang, Y. Q. (2017). Progress of in vivo studies on the systemic toxicities induced by titanium dioxide nanoparticles. Toxicol Res. 6, 115-133. doi: 10.1039/C6TX00338A

Kenney, S. C. (2007). "Reactivation and lytic replication of EBV," in Human Herpesviruses: Biology, Therapy, and Immunoprophylaxis, eds A. Arvin, G. Campadelli-Fiume, E. Mocarski, P. S. Moore, B. Roizman, R. Whitley, and K. Yamanishi (Cambridge: Cambridge University Press), 403-433.

Kropski, J. A., Lawson, W. E., and Blackwell, T. S. (2012). Right place, right time: the evolving role of herpesvirus infection as a "second hit" in idiopathic pulmonary fibrosis. Am. J. Physiol. Lung Cell Mol. Physiol. 302, L441-L444. doi: 10.1152/ajplung.003 35.2011

Lieberman, P. M. (2016). Epigenetics and genetics of viral latency. Cell Host Microbe 19, 619-628. doi: 10.1016/j.chom.2016.04.008

Liu, X. F., Wang, X., Yan, S., Zhang, Z., Abecassis, M., and Hummel, M. (2013). Epigenetic control of cytomegalovirus latency and reactivation. Viruses 5, 1325-1345. doi: 10.3390/v5051325

Maizels, R. M., and Gause, W. C. (2014). Immunology. How helminths go viral. Science 345, 517-518. doi: 10.1126/science. 1258443

Marsland, B. J., and Gollwitzer, E. S. (2014). Host-microorganism interactions in lung diseases. Nat. Rev. Immunol. 14, 827-835. doi: 10.1038/ nri3769

Meneghin, A., and Hogaboam, C. M. (2007). Infectious disease, the innate immune response, and fibrosis. J. Clin. Invest. 117, 530-538. doi: 10.1172/JCI30595

Miller, M. R., Raftis, J. B., Langrish, J. P., McLean, S. G., Samutrtai, P., Connell, S. P., et al. (2017). Inhaled nanoparticles accumulate at sites of vascular disease. ACS Nano 11, 4542-4552. doi: 10.1021/acsnano.6b08551

Morgenstern, V., Zutavern, A., Cyrys, J., Brockow, I., Koletzko, S., Kramer, U., et al. (2008). Atopic diseases, allergic sensitization, and exposure to trafficrelated air pollution in children. Am. J Respir. Crit. Care Med. 177, 1331-1337. doi: $10.1164 / \mathrm{rccm} .200701-036 \mathrm{OC}$

Murata, T. (2014). Regulation of Epstein-Barr virus reactivation from latency. Microbiol. Immunol. 58, 307-317. doi: 10.1111/1348-0421.12155
Naik, P. K., and Moore, B. B. (2010). Viral infection and aging as cofactors for the development of pulmonary fibrosis. Expert Rev. Respir. Med. 4, 759-771. doi: $10.1586 /$ ers. 10.73

Pallardy, M. J., Turbica, I., and Biola-Vidamment, A. (2017). Why the immune system should be concerned by nanomaterials? Front. Immunol. 8:544. doi: 10.3389/fimmu.2017.00544

Pellett, P. E., and Roizman, B. (2013). "Herpesviridae, ” in Fields - Virology, eds D. M. Knipe, P. M. Howley, D. E. Griffin, M. A. Martin, and R. A. Lamb, et al. (Philadelphia, PA: Lippincott Williams \& Wilkins), 1802-1822.

Reese, T. A. (2016). Coinfections: another variable in the herpesvirus latencyreactivation dynamic. J. Virol. 90, 5534-5537. doi: 10.1128/JVI.01865-15

Reese, T. A., Wakeman, B. S., Choi, H. S., Hufford, M. M., Huang, S. C., Zhang, X., et al. (2014). Helminth infection reactivates latent gammaherpesvirus via cytokine competition at a viral promoter. Science 345, 573-577. doi: 10.1126/science.1254517

Roizman, B., Knipe, D. M., and Whitley, R. J. (2013). "Herpes Simplex Viruses," in Fields - Virology, eds D. M. Knipe, P. M., Howley, D. E., Griffin, M. A., Martin, R. A., and Lamb, et al.( Philadelphia: Lippincott Williams \& Wilkins), 1823-1897.

Roizman, B., and Whitley, R. J. (2013). An inquiry into the molecular basis of HSV latency and reactivation. Annu. Rev. Microbiol. 67, 355-374. doi: 10.1146/annurev-micro-092412-155654

Sattler, C., Moritz, F., Chen, S., Steer, B., Kutschke, D., Irmler, M., et al. (2017). Nanoparticle exposure reactivates latent herpesvirus and restores a signature of acute infection. Part Fibre Toxicol. 14, 2-0181. doi: 10.1186/s12989-016-0181-1

Seaton, A., Tran, L., Aitken, R., and Donaldson, K. (2010). Nanoparticles, human health hazard and regulation. J. R. Soc. Interface 7 (Suppl.1), S119-S129. doi: 10.1098/rsif.2009.0252.focus

Sese, L., Nunes, H., Cottin, V., Sanyal, S., Didier, M., Carton, Z., et al. (2018). Role of atmospheric pollution on the natural history of idiopathic pulmonary fibrosis. Thorax 73, 145-150. doi: 10.1136/thoraxjnl-2017-209967

Siroux, V., and Crestani, B. (2018). Is chronic exposure to air pollutants a risk factor for the development of idiopathic pulmonary fibrosis? Eur. Respir. J. 51, 13993003-13992017. doi: 10.1183/13993003.02663-2017

Stinski, M. F., and Meier, J. L. (2007). "Immediate-early viral gene regulation and function," in Human Herpesviruses: Biology, Therapy, and Immunoprophylaxis, eds A. Arvin, G. Campadelli-Fiume, E. Mocarski, P. S. Moore, B. Roizman, R. Whitley, and K. Yamanishi (Cambridge: Cambridge University Press), 241-263.

Vannella, K. M., and Moore, B. B. (2008). Viruses as co-factors for the initiation or exacerbation of lung fibrosis. Fibrogenesis Tissue Repair. 1, 2. doi: 10.1186/1755-1536-1-2

You, R., Ho, Y. S., Hung, C. H., Liu, Y., Huang, C. X., Chan, H. N., et al. (2018). Silica nanoparticles induce neurodegeneration-like changes in behavior, neuropathology, and affect synapse through MAPK activation. Part Fibre Toxicol. 15, 28-0263. doi: 10.1186/s12989-018-0263-3

Conflict of Interest Statement: The authors declare that the research was conducted in the absence of any commercial or financial relationships that could be construed as a potential conflict of interest.

Copyright (c) 2019 Stoeger and Adler. This is an open-access article distributed under the terms of the Creative Commons Attribution License (CC BY). The use, distribution or reproduction in other forums is permitted, provided the original author(s) and the copyright owner(s) are credited and that the original publication in this journal is cited, in accordance with accepted academic practice. No use, distribution or reproduction is permitted which does not comply with these terms. 